\title{
Total Phenolic and Flavonoid Content and Antioxidant Activities of Ten Malaysian Wild Mushrooms
}

\author{
Jinting Azieana', Mohd Noor Zainon ${ }^{1,2}$, Abdullah Noriham ${ }^{2,3}$, Mat Nor Rohana ${ }^{1}$ \\ ${ }^{1}$ Faculty of Applied Sciences, School of Biology, Universiti Teknologi MARA, Shah Alam, Malaysia \\ ${ }^{2}$ Malaysia Institute of Transport, Universiti Teknologi MARA, Shah Alam, Malaysia \\ ${ }^{3}$ Faculty of Applied Sciences, School of Industrial Technology, Universiti Teknologi MARA, Shah Alam, Malaysia \\ Email: dzainonmn@salam.uitm.edu.my
}

How to cite this paper: Azieana, J., Zainon, M.N., Noriham, A. and Rohana, M.N. (2017) Total Phenolic and Flavonoid Content and Antioxidant Activities of Ten Malaysian Wild Mushrooms. Open Access Library Journal, 4: e3987.

https://doi.org/10.4236/oalib.1103987

Received: September 28, 2017

Accepted: November 20, 2017

Published: November 23, 2017

Copyright $\odot 2017$ by authors and Open Access Library Inc.

This work is licensed under the Creative Commons Attribution International License (CC BY 4.0).

http://creativecommons.org/licenses/by/4.0/

\begin{abstract}
Mushrooms have been studied and found to accumulate a variety of secondary metabolites with antioxidant activities such as phenolic compounds. Besides phenolics, other bioactive components such as flavanoids from mushrooms are also generally associated with antioxidant activities. Previous studies have reported the association of mushrooms with their antioxidant potentials. However, very few studies are related to unexplored Malaysian wild mushrooms as a new potential source of antioxidant for which to best of our knowledge, no records are available. In this study, ten Malaysian wild mushrooms were collected from the forests around Selangor and Sabah and their potential antioxidant activity were evaluated. The total phenolic content and total flavonoid content were quantified. Antioxidant activities of the mushroom extracts were analyzed by Ferric Reducing Antioxidant Power (FRAP) and 2,2-diphenylpicrylhydrazyl (DPPH) assays for their iron-reducing capacity and free-radical scavenging capacity. The total phenolic content of all ten mushrooms ranged from $0.015-0.075 \mathrm{mg} \mathrm{GAE} / \mathrm{g}$ dried extract and the total flavonoid content ranged from $0.025-0.131 \mathrm{mg} \mathrm{QE} / \mathrm{g}$ dried extract. The FRAP values lies between $0.859-2.929 \mu \mathrm{M}$ TE/g dried extract and the percentage of inhibition observed from DPPH assay ranged from $2 \%-57 \%$ respectively. There is a positive correlation between total phenolic content and antioxidant activities of these mushroom extracts.
\end{abstract}

\section{Subject Areas}

Food Science \& Technology, Mycology, Plant Science

\section{Keywords}

Total Phenolic, Total Flavonoid, FRAP, DPPH, Mushrooms 


\section{Introduction}

Antioxidants are compounds that delay or inhibit the oxidation of other molecules by inhibiting the initiation of oxidizing chain reactions propagation [1]. The antioxidant compounds play a major role in the prevention of diseases such as cancer, cataracts, cerebral pathologies and rheumatoid arthritis [2]. Mushrooms have been studied and found to accumulate a variety of secondary metabolites with antioxidant activities such as phenolic compounds. Phenolic compounds have the ability to neutralize free radicals [3] which are responsible for oxidative damage in the human body. In order to reduce oxidative damage of free radicals in the human body, synthetic antioxidants such as butylated hydroxyl anisole (BHA) and butylated hydroxyl toluene (BHT) are used. However, the uses of these synthetic antioxidants in food have been restricted due to their carcinogenic effects [3] which have also been suspected to be responsible for liver damage [4]. Thus, the development and utilization of antioxidant substances from natural resources has increased. Mushrooms have been reported to contain a wide variety of free radical scavenging molecules such as polysaccharides and polyphenols [5]. Besides phenolics, flavonoids from mushrooms can also act as free radical scavengers to terminate the radical chain reactions that occur during the oxidation of triglycerides in the food system [6]. Flavonoids have anticarcinogenic, antimutagenic and cardioprotective effects that generally associated with antioxidant properties [7]. Several different methods have been developed to measure the antioxidant activities of compound. These methods include 2,2-diphenylpicrylhydrazyl (DPPH) and Ferric Reducing Antioxidant Power (FRAP). FRAP method was used to measure the iron-reducing capacity of mushrooms therefore it reveals the electron donating potential of the extracts. The ferrous-2,4,6-tri(2-pyridyl)-s-triazine [Fe(II)-TPTZ] complex formed upon the reduction of ferric-2,4,6-tri(2-pyridyl)-s-triazine [Fe(III)-TPTZ] has an intensive blue color and can be measured spectrophotometrically at $593 \mathrm{~nm}$ [8]. DPPH method was used to evaluate the free-radical scavenging capacity of the mushrooms. It is described as rapid, simple and convenient method for measuring the ability of different compounds to act as free radical scavengers or hydrogen donors [9]. This spectrophotometric assay uses 2,2-diphenylpicrylhydrazyl $(\mathrm{DPPH})$ radical as reagent. Hydrogen atom or electron donation ability of the mushrooms will be measured from the bleaching of the purple-colored ethanol solution of DPPH [2]. The objective of this study was to evaluate the antioxidant properties of ten Malaysian wild mushrooms based on the estimation of total phenolic and flavanoid content and analysis by FRAP and DPPH assays.

\section{Materials and Methods}

\subsection{Sample Collection}

Ten species of mushrooms were collected from the forests around Selangor and Sabah. 


\subsection{Preparation of Mushroom Extracts}

Organic extraction of mushroom was carried out according to the method described by Khlood et al. [10]. Fresh mushroom was minced and dried under vacuum at room temperature for 2 hours. Accurately, $40 \mathrm{~mL}$ of methanol and chloroform were added at 1:1 volume ratio. The homogenate was agitated for 2 hours, filtered with normal filter paper, refluxed for 3 hours or until completely dry using a rotary evaporator at $50^{\circ} \mathrm{C}$. The dried extract was re-dissolved in $100 \%$ dimethyl sulfoxide (DMSO) for highest concentration, diluted to $1 \mathrm{mg} / \mathrm{mL}$ and finally stored at $4^{\circ} \mathrm{C}$.

\subsection{Estimation of Total Phenolic Content (TPC)}

The Folin-Ciocalteu method was used for determination of total phenolic content (TPC) as described by Harbourne et al. [11] with slight modifications. Accurately, $0.1 \mathrm{~mL}$ of sample or standard was mixed with $0.5 \mathrm{~mL}$ of Folin-Ciocalteu reagent. Then, $1.5 \mathrm{~mL}$ of $7.5 \%$ sodium and $7.8 \mathrm{~mL}$ of distilled water was added to the mixture and mix thoroughly. The mixture was allowed to stand at room temperature in a dark environment for 2 hours. Absorbance was measured against the blank reagent at $725 \mathrm{~nm}$ by using Helios Zeta UV-VIS Spectrophotometer from Thermo Fisher Scientific, USA. Gallic acid was used for the calibration curve with a concentration range of $50-1000 \mu \mathrm{l} / \mathrm{mL}\left(\mathrm{R}^{2}=0.99\right)$. The TPC of the sample was expressed as mg gallic acid equivalent (mg GAE)/g of dried extract. All experiments were performed in triplicates.

\subsection{Estimation of Total Flavonoid Content (TFC)}

Total flavonoid content (TFC) was determined following the method by Singh et al. [12]. Accurately, $1 \mathrm{~mL}$ of sample or standard was diluted with $4 \mathrm{~mL}$ distilled water and $0.3 \mathrm{~mL}$ of $5 \%$ sodium nitrate solution was added. After 6 minutes, 0.3 $\mathrm{mL}$ of a $10 \%$ aluminium chloride solution was added to the mixture. The mixture was incubated at room temperature for 5 minutes. Then, $2 \mathrm{~mL}$ of $1 \mathrm{M}$ sodium hydroxide was added to the mixture after 5 minutes of incubation. The mixture was vortexed thoroughly and the absorbance of the pink colour was measured at $510 \mathrm{~nm}$ against a blank by using Helios Zeta UV-VIS Spectrophotometer. Quercetin was used for the calibration curve with a concentration range of $10-1000 \mu \mathrm{g} / \mathrm{mL}\left(R^{2}=0.99\right)$. Results were expressed as $\mathrm{mg}$ quercetin equivalent (mg QE)/g of dried extract. All experiments were carried out in triplicates.

\subsection{Analysis of Antioxidant Activities by FRAP Method}

The FRAP assay was carried out according to the procedure by Deetae et al. [13]. The FRAP working solution was freshly prepared. Accurately, $25 \mathrm{ml}$ Lacetate buffer ( $3.1 \mathrm{~g}$ sodium acetate and $16 \mathrm{~mL}$ concentrated Acetic acid per $1 \mathrm{~L}$ of buffer solution) was mixed with $2.5 \mathrm{~mL}$ 2,4,6-tripyridyl-s-triazine solution (10 $\mathrm{mM} / \mathrm{L}$ 2,4,6-tripyridyl-s-triazine in $40 \mathrm{mM} / \mathrm{L}$ hydrochloric acid) and $2.5 \mathrm{~mL}$ iron (III) chloride solution ( $20 \mathrm{mM} / \mathrm{L}$ iron (III) chloride hexahydrate in distilled wa- 
ter) as the FRAP working solution. Briefly, $0.1 \mathrm{~mL}$ sample or standard was mixed with $3 \mathrm{~mL}$ FRAP reagent and $3 \mathrm{~mL}$ distilled water. The mixture was then incubated in the dark at $37^{\circ} \mathrm{C}$ for 8 minutes. The absorbance at $593 \mathrm{~nm}$ was recorded using Helios Zeta UV-VIS Spectrophotometer. The total antioxidant capacity of samples was determined against a standard of known FRAP value and was expressed as $\mu \mathrm{M}$ of trolox equivalent ( $\mu \mathrm{M} \mathrm{TE}) / \mathrm{g}$ of dried extract. All experiments were carried out in triplicates.

\subsection{Analysis of Antioxidant Activities by DPPH Method}

The DPPH method was performed as described by Nuengchamnong and Ingkaninan [14]. Accurately, $0.1 \mathrm{~mL}$ of sample or standard was added to $2.9 \mathrm{~mL}$ of $0.05 \mathrm{mM}$ methanol solution of DPPH and incubated at room temperature for 30 minutes in the dark. After incubation at room temperature, the absorbance of the sample or standard was measured where methanol was used as blank at 515 nm by using Helios Zeta UV-VIS Spectrophotometer. All experiments were performed in triplicates. The scavenging activity on DPPH was calculated and presented as percent of inhibition.

\subsection{Statistical Analysis}

All experiments were carried out in triplicates. Data obtained were analyzed by using one-way analysis of variance (ANOVA) and Pearson's correlation coefficient was performed. Significant differences between the means at 95\% ( $p<$ $0.05)$ level were considered statistically significant. Data was recorded as mean \pm standard deviation.

\section{Results and Discussion}

\subsection{Mushroom Collections}

Figure 1 show ten wild mushrooms collected from Selangor and Sabah forests. All mushrooms were found to be saprophytic as they live on dead trunk.

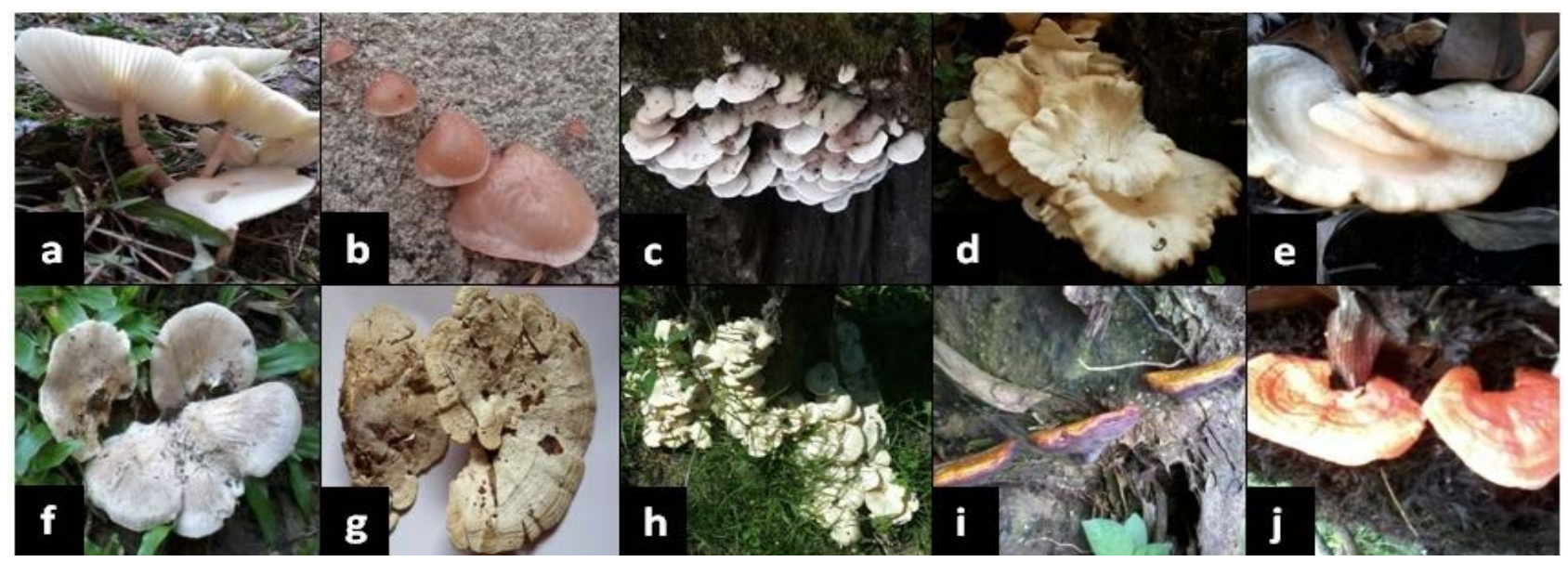

Figure 1. Ten wild mushrooms collected from Selangor and Sabah forests. (a) Mushroom A. (b) Mushroom B. (c) Mushroom C. (d) Mushroom D. (e) Mushroom E. (f) Mushroom F. (g) Mushroom G. (h) Mushroom H. (i) Mushroom I. (j) Mushroom J. 


\subsection{Total Phenolic Content (TPC), Total Flavonoid Content (TFC) and Antioxidant Activities by FRAP and DPPH of Ten Mushroom Extracts}

Total polyphenols (TP) were the major naturally occurring antioxidant components found in many edible mushrooms which may contribute directly to antioxidative action because of their scavenging ability due to their hydroxyl group. The standard curve of gallic acid was prepared and total phenolic content of 10 different mushroom extracts were calculated based on this standard and presented as gallic acid equivalents (GAE) per gram of dry extract. The 10 different mushroom extracts showed TPC ranging from 0.015 - $0.075 \mathrm{mg} \mathrm{GAE} / \mathrm{g}$ (Table 1). Among the 10 mushroom extracts tested, mushroom extract $J$ showed highest TPC with $0.075 \mathrm{mg}$ GAE/g followed by mushroom extract C $(0.064 \mathrm{mg}$ GAE/g) and mushroom extract $\mathrm{H}(0.062 \mathrm{mg} \mathrm{GAE} / \mathrm{g})$ with no significant differences. The lowest phenolic content was found in mushroom extract $\mathrm{E}$ with 0.015 mg GAE/g.

Total flavonoid content was calculated using quercetin as a standard and the results are expressed as $\mathrm{mg}$ of quercetin equivalents per gram of extract. The total flavonoid content of 10 mushroom extracts ranged from $0.025-0.131 \mathrm{mg}$ $\mathrm{QE} / \mathrm{g}$ (Table 1). It showed that mushrooms extract $\mathrm{C}$ which has high total phenol content also exhibited high total flavonoid content $(0.131 \mathrm{mg} \mathrm{QE} / \mathrm{g})$ with no significant different with mushroom extract $\mathrm{J}(0.122 \mathrm{mg} \mathrm{QE} / \mathrm{g})$ as compared to the other 8 mushroom extracts studied. This followed by mushroom extract $\mathrm{H}$ with $0.078 \mathrm{mg} \mathrm{QE} / \mathrm{g}$. The lowest flavonoid content was found in mushroom extract $\mathrm{E}$ and I with no significant different $(0.026 \mathrm{mg} \mathrm{QE} / \mathrm{g})$.

Table 1. Total phenolic content (TPC), total flavonoid content (TFC) and antioxidant activities by FRAP and DPPH of ten mushroom extracts.

\begin{tabular}{|c|c|c|c|c|}
\hline \multirow[b]{2}{*}{$\begin{array}{c}\text { Mushroom } \\
\text { Extract }\end{array}$} & \multicolumn{4}{|c|}{ Assay } \\
\hline & $\begin{array}{c}\text { TPC } \\
\text { (mg GAE/g dried } \\
\text { extract) }\end{array}$ & $\begin{array}{c}\text { TFC } \\
\text { (mg QE/g dried } \\
\text { extract) }\end{array}$ & $\begin{array}{c}\text { FRAP } \\
(\mu \mathrm{M} \text { TE/g dried } \\
\text { extract) }\end{array}$ & $\begin{array}{c}\text { DPPH } \\
\text { ( } \mu \mathrm{g} / \mathrm{g} \text { dried } \\
\text { extract) }\end{array}$ \\
\hline A & $0.037 \pm 0.003^{c}$ & $0.055 \pm 0.006^{c}$ & $1.499 \pm 0.111^{\mathrm{c}}$ & $11.204 \pm 1.885^{\mathrm{d}}$ \\
\hline B & $0.026 \pm 0.004^{\mathrm{d}}$ & $0.038 \pm 0.001^{\mathrm{d}}$ & $1.262 \pm 0.131^{\mathrm{c}}$ & $17.112 \pm 1.147^{\mathrm{c}}$ \\
\hline $\mathrm{C}$ & $0.064 \pm 0.011^{\mathrm{b}}$ & $0.131 \pm 0.014^{\mathrm{a}}$ & $2.579 \pm 0.093^{\mathrm{b}}$ & $55.612 \pm 1.515^{\mathrm{a}}$ \\
\hline $\mathrm{D}$ & $0.029 \pm 0.002^{\mathrm{d}}$ & $0.057 \pm 0.003^{c}$ & $1.165 \pm 0.082^{c}$ & $9.659 \pm 1.576^{\mathrm{d}}$ \\
\hline $\mathrm{E}$ & $0.015 \pm 0.001^{\mathrm{e}}$ & $0.026 \pm 0.004^{\mathrm{e}}$ & $0.959 \pm 0.128^{c, d}$ & $3.586 \pm 0.190^{\mathrm{e}}$ \\
\hline $\mathrm{F}$ & $0.024 \pm 0.002^{\mathrm{d}}$ & $0.025 \pm 0.002^{\mathrm{e}}$ & $1.049 \pm 0.131^{c, \mathrm{~d}}$ & $6.305 \pm 0.598^{\mathrm{d}, \mathrm{e}}$ \\
\hline G & $0.025 \pm 0.004^{\mathrm{d}}$ & $0.058 \pm 0.002^{c}$ & $0.935 \pm 0.102^{\mathrm{d}}$ & $9.180 \pm 1.578^{d}$ \\
\hline $\mathrm{H}$ & $0.062 \pm 0.010^{\mathrm{b}}$ & $0.078 \pm 0.010^{\mathrm{b}}$ & $2.929 \pm 0.111^{\mathrm{a}}$ & $44.185 \pm 0.694^{\mathrm{b}}$ \\
\hline I & $0.023 \pm 0.003^{\mathrm{d}}$ & $0.026 \pm 0.001^{\mathrm{e}}$ & $0.859 \pm 0.076^{\mathrm{d}}$ & $6.610 \pm 0.912^{\mathrm{d}, \mathrm{e}}$ \\
\hline $\mathrm{J}$ & $0.075 \pm 0.001^{\mathrm{a}}$ & $0.122 \pm 0.010^{\mathrm{a}}$ & $1.469 \pm 0.128^{c}$ & $1.770 \pm 0.032^{\mathrm{f}}$ \\
\hline
\end{tabular}

${ }^{\mathrm{a}-\mathrm{g}}$ Mean values \pm standard deviations represented by the same letters within the same column are significantly different $(\mathrm{p}<0.05)$. 
The iron-reducing capacity of the mushroom extracts were determined by the FRAP method, which depends upon the reduction of a ferric-2,4,6-tri(2-pyridyl)s-triazine [Fe(III)-TPTZ] complex to its ferrous-2,4,6-tri(2-pyridyl)-s-triazine [Fe(II)-TPTZ] that has an intensive blue color and can be monitored at $593 \mathrm{~nm}$ [8]. The range of total antioxidant capacity of mushroom extracts lies between 0.859 - $2.929 \mu \mathrm{M} \mathrm{TE} / \mathrm{g}$ (Table 1). Among all the mushroom extracts, it was showing that mushroom extract $\mathrm{H}$ which also contain high phenolic and flavonoid contents also exhibit high value of FRAP with $2.929 \mu \mathrm{M}$ TE/g followed by mushroom extract C with $2.579 \mu \mathrm{M}$ TE/g. Similar trends have been reported by Tripathy et al. [16], where maximum total phenolic content seen for wild mushroom I. radiates, also exhibit high value of FRAP. The lowest value of FRAP was found in mushroom extract I $(0.859 \mu \mathrm{M} \mathrm{TE} / \mathrm{g})$. However, there is no significant differences between this value with the value obtained for mushroom extract $\mathrm{E}(0.959 \mu \mathrm{M} \mathrm{TE} / \mathrm{g})$, mushroom extract $\mathrm{F}(1.049 \mu \mathrm{M} \mathrm{TE} / \mathrm{g})$, and mushroom extract G $(0.935 \mu \mathrm{M} \mathrm{TE} / \mathrm{g})$.

The free radical scavenging capacity of the mushroom extracts was measured by DPPH assay where the stable, purple-colored radical DPPH were reduced into the yellow-colored DPPH-H. The percentage of inhibition of mushroom extract was shown in Figure 2. Mushroom $\mathrm{C}$ shows the highest percentage of radical scavenging activity ranging from $50 \%$ to $60 \%$, followed by mushroom extract $\mathrm{H}$ with $40 \%$ to $50 \%$ of radical scavenging activity. These results indicate that the antioxidants in these mushrooms extracts are moderate DPPH radical scavengers. There was significant difference of highly percentage of inhibition observed between these two mushrooms extracts compared to the others. High inhibition percentage indicates higher antioxidant activity of the extract. Higher activity of the extract may be due to the presence of high hydroxyl groups, which is proportionate to their phenolic content [15]. However, mushroom extract J shows the lowest percentage of inhibition even though it yields the highest TP content. This may due to the bright orange colour of the extract which may in-

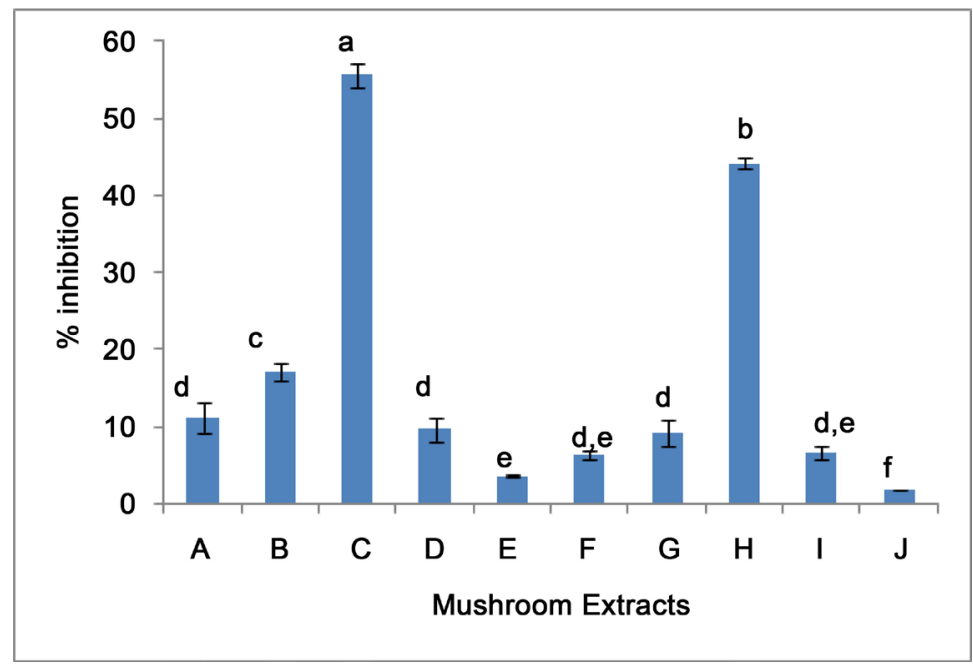

Figure 2. The percentage of inhibition of mushroom extracts by DPPH. 
Table 2. Pearson's correlation coefficient (R) between antioxidant activities of wild mushrooms.

\begin{tabular}{ccc}
\hline & FRAP & DPPH \\
\hline TPC & 0.760 & 0.540 \\
TFC & 0.661 & 0.555 \\
\hline
\end{tabular}

terfere with purple-colored solution of DPPH.

\subsection{Antioxidant Activities of Mushroom Extracts in Relation to Total Phenolic and Total Flavonoid}

Antioxidant capacities can be related to the total phenolic content of the mushroom extracts. Puttaraju et al. [17] suggest that the antioxidant activity was varied among the mushroom extracts probably due to the combinational effect of different phenolic compounds in the plant itself. The correlation coefficient was used to measure the degree or strength between the total phenolic content (TPC) and total flavonoid content (TFC) of mushroom extracts with FRAP and DPPH. Correlations were divided into categories based on the value of the strength to which the two variables are related: very strong $(1.0-0.80)$, strong $(0.79-0.60)$, moderate $(0.59-0.40)$, weak $(0.39-0.20)$, and very weak $(0.19-0.00)$ as suggested by Evans [18]. Table 2 demonstrates the correlation coefficients, $\mathrm{R}$, between values obtained from each assay.

Total phenolic content (TPC) were strongly correlated with FRAP $(r=0.760)$ and moderately correlated with DPPH $(r=0.540)$. A moderate correlation was noted between the total flavonoid content (TFC) with FRAP $(r=0.661)$ and DPPH $(r=0.555)$. This may suggest that phenolic was the major antioxidant components in the mushroom extracts that contributed to their antioxidant activities. This result was consistent with previous findings that reported positive correlations between TPC and scavenging ability of DPPH in mushrooms [19].

\section{Conclusion}

This study revealed that some of wild mushrooms from Selangor and Sabah forests contain bioactive compounds that associate with their antioxidant properties. A moderate correlation between phenolic content and antioxidant activities suggest that phenolic was a major compound that contributed to the antioxidant activities of the mushroom extracts. However, some wild mushrooms are poisonous therefore, further study are required to evaluate the toxicity of the mushrooms. An intensive study on molecular identification of the mushrooms is needed for documentation purposes.

\section{Acknowledgements}

The authors would like to acknowledge Universiti Teknologi MARA (UiTM) Shah Alam Selangor and Malaysia Institute of Transport Universiti Teknologi MARA (UiTM) Shah Alam Selangor for supporting this project. 


\section{References}

[1] Asatiani, M.D., Elisashvili, V., Songulashvili, G., Reznick, A.Z. and Wasser, S.P. (2010) Higher Basidiomycetes Mushrooms as a Source of Antioxidants. Progress in Mycology, 311-326. https://doi.org/10.1007/978-90-481-3713-8_11

[2] Stef, D.S., Gergen, I., Trasca, T.I., Harmanescu, M., Lavinia, S., Ramona, B. and Heghedus, M.G. (2009) Total Antioxidant and Radical Scavenging Capacities for Different Medicinal Herbs. Romanian Biotechnological Letters, 14, 4704-4709.

[3] Yim, H.S., Chye, F.Y., Tan, C.T., Ng, Y.C. and Ho, C.W. (2010) Antioxidant Activities and Total Phenolic Content of Aqueous Extract of Pleurotus ostreatus (Cultivated Oyster Mushroom). Malaysian Journal of Nutrition, 16, 281-291.

[4] Yeh, J.-Y., Hsieh, L.-H., Wu, K.-T. and Tsai, C.-F. (2011) Antioxidant Properties and Antioxidant Compounds of Various Extracts from the Edible Basidiomycete Grifola frondosa (Maitake). Molecules, 16.

https://doi.org/10.3390/molecules16043197

[5] Cui, Y., Kim, D.S. and Park, K.C. (2005) Antioxidant Effects of Inonotus obliquus. Journal of Ethnopharmacology, 96, 79-85. https://doi.org/10.1016/j.jep.2004.08.037

[6] Barros, L., Cruz, T., Baptista, P., Estevinho, L.M. and Ferreira, I.C.F.R. (2008) Wild and Commercial Mushrooms as Source of Nutrients and Nutraceuticals. Food and Chemical Toxicology, 46, 2742-2747. https://doi.org/10.1016/j.fct.2008.04.030

[7] Aaby, K., Hvattum, E. and Skrede, G. (2003) Analysis of Flavonoids and Other Phenolic Compounds Using High-Performance Liquid Chromatography with Coulometric Array Detection: Relationship to Antioxidant Activity.

[8] Benzie, I.F.F. and Strain, J.J. (1996) The Ferric Reducing Ability of Plasma (FRAP) as a Measure of "Antioxidant Power": The FRAP Assay. Analytical Biochemistry, 238, 70-76. https://doi.org/10.1006/abio.1996.0292

[9] Marinova, G. and Batchvarov, V. (2011) Evaluation of the Methods for Determination of the Free Radical Scavenging Activity by DPPH. Bulgarian Journal of Agricultural Science, 17.

[10] El Bohi, K.M., Sabik, L., Muzandu, K., Shaban, Z., Soliman, M., Ishizuka, M., Shoichi, F., et al. (2005) Antigenotoxic Effect of Pleurotus cornucopiae Extracts on the Mutagenesis of Salmonella typhimurium TA98 Elicited by benzo[a] Pyrene and Oxidative DNA Lesions in V79 Hamster Lung Cells. Japanese Journal of Veterinary Research, 52, 163-175.

[11] Harbourne, N., Marete, E., Jacquier, J.C. and O'Riordan, D. (2009) Effect of Drying Methods on the Phenolic Constituents of Meadowsweet (Filipendula ulmaria) and Willow (Salix alba). LWT-Food Science and Technology, 42, 1468-1473. https://doi.org/10.1016/j.lwt.2009.05.005

[12] Singh, V., Guizani, N., Essa, M.M., Hakkim, F.L. and Rahman, M.S. (2012) Comparative Analysis of Total Phenolics, Flavonoid Content and Antioxidant Profile of Different Date Varieties (Phoenix dactylifera L.) from Sultanate of Oman. International Food Research Journal, 19, 1063-1070.

[13] Deetae, P., Parichanon, P., Trakunleewatthana, P., Chanseetis, C. and Lertsiri, S. (2012) Antioxidant and Anti-Glycation Properties of Thai Herbal Teas in Comparison with Conventional Teas. Food Chemistry, 133, 953-959.

https://doi.org/10.1016/j.foodchem.2012.02.012

[14] Nuengchamnonga, N. and Ingkaninan, K. (2010) Analytical Methods On-Line HPLC-MS-DPPH Assay for the Analysis of Phenolic Antioxidant Compounds in Fruit Wine: Antidesma thwaitesianum Muell. Food Chemistry, 118, 147-152. 
https://doi.org/10.1016/j.foodchem.2009.04.069

[15] Kothari, V. and Seshadri, S. (2010) Antioxidant Activity of Seed Extracts of Annona squamosa and Carica papaya. Nutrition \& Food Science, 40.

[16] Tripathy, S.S., Rajoriya, A. and Gupta, N. (2014) Wild Mushrooms of Odisha: Prospective Candidates of Antioxidant Sources. Advances in Plants \& Agriculture Research, 1.

[17] Puttaraju, N.G., Venkateshaiah, S.U., Dharmesh, S.M., Urs, S.M. and Somansundaram, R. (2006) Antioxidant Activity of Indigenous Edible Mushrooms. Journal of Agricultural and Food Chemistry, 54, 9764-9772. https://doi.org/10.1021/jf0615707

[18] Evans, J.D. (1996) Straightforward Statistics for the Behavioral Sciences. Brooks/ Cole Pub. Co., Pacific Grove.

[19] Cheung, L.M., Cheung, P.C.K. and Ooi, V.E.C. (2003) Antioxidant Activity and Total Phenolics of Edible Mushroom Extracts. Food Chemistry, 81, 249-255. https://doi.org/10.1016/S0308-8146(02)00419-3

Submit or recommend next manuscript to OALib Journal and we will provide best service for you:

- Publication frequency: Monthly

- 9 subject areas of science, technology and medicine

- Fair and rigorous peer-review system

- Fast publication process

- Article promotion in various social networking sites (LinkedIn, Facebook, Twitter, etc.)

- Maximum dissemination of your research work

Submit Your Paper Online: Click Here to Submit

Or Contact service@oalib.com 